
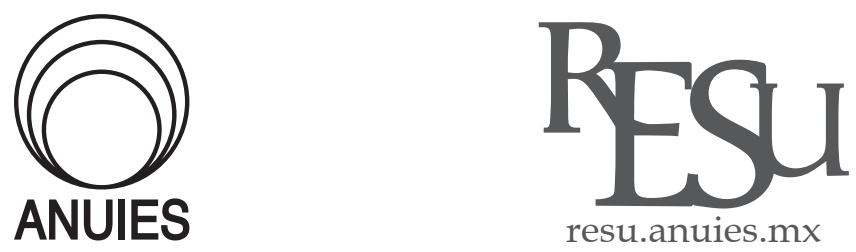

REVITA DEU
EDLCACIÓN
SUPERIOR

RESEÑA

\title{
La formación de investigadores en el Departamento de Biología Celular del Cinvestav*
}

\author{
Ivett Liliana Estrada Mota** \\ * Título en inglés: *The training of researchers in the Department of Cell Biology, Cinvestav \\ Reseña obtenida de: González Quiroz, Julia (2019). Apropiarse de un quehacer. La formación de investigadores en el \\ Departamento de Biología Celular del Cinvestav. México: ANUIES \\ ** Universidad Autónoma de Yucatán, Mérida, Yucatán, México. \\ Correo electrónico: ivett.estrada@correo.uady.mx
}

L a obra de Julia González Quiroz, Apropiarse de un quehacer. La formación - de investigadores en el Departamento de Biología Celular del Cinvestav, es resultado de un cuidadoso trabajo de investigación centrado en los procesos de formación que acontecen en un mundo social muy peculiar: el mundo de la ciencia. La lectura que a continuación les comparto representa sólo uno de los posibles acercamientos al texto, en tanto soy consciente del papel de la mediación de nuestros esquemas de referencia y experiencias de vida en nuestros análisis e interpretaciones. Atendiendo a este supuesto, iniciaré con la exposición de los planteamientos de la autora que me fueron significativos y considero de interés entre quienes nos interesamos en el estudio de los grupos científicos y su quehacer. En un segundo momento, referiré algunas de las múltiples aportaciones al debate en torno al tema que estimo contribuye la autora con su obra.

Pienso que el mejor medio para introducirles a esta obra es a través de su título. Cuando se concluye la lectura del libro es posible reconocer en aquél la manera ejemplar como la autora logró condensar su contenido. La frase inicial, apropiarse de un quehacer, pensada como sinónimo de tomar para sí, o adueñarse, en este caso, de una actividad profesional como lo es el oficio de científico, brinda la pauta para reconocer una de las principales aseveraciones de Julia González sobre su propuesta para abordar la formación de inves- 
tigadores. La autora sostiene que ésta no ha de ser entendida como "[...] la conclusión de un periodo de estudio legitimado por un título o un certificado $[\ldots]$ "; antes bien, habrá que pensarla como "[...] una actividad permanente que el sujeto reafirma en la propia práctica profesional". (González: 13)

En su carácter de actividad permanente, apropiarse de un quehacer es una frase sobre la formación de investigadores que encierra una noción de proceso. Es una expresión que la autora asocia a una compleja trama que incluye, primordialmente, la construcción de vínculos entre aprendices y maestros. Estos vínculos configuran relaciones entre ellos donde no sólo se movilizan contenidos y habilidades disciplinares, sino también afectos, emociones, valores y normas en la búsqueda de la transmisión de un ideal científico. Estas relaciones se sostienen a través de una cultura institucional y de tradiciones disciplinares, e implican un tránsito de los maestros y aprendices por periodos y espacios de formación con funciones y significados particulares para la construcción de sus carreras científicas.

Desde mi lectura, cuando la autora centra la atención en el carácter de la formación de investigadores como una reafirmación de la práctica profesional, atiende a uno de sus intereses centrales claramente desarrollado a lo largo de la obra: dar cuenta de los procesos identitarios que se juegan en la formación. Dicho de otro modo: de cómo aprendices y maestros llegan a asumirse como científicos y miembros de una comunidad científica de una disciplina particular. En este proceso formativo, la autora sostiene la existencia de una relación de interdependencia entre los iniciados y tutores, en la cual median representaciones de modelos ideales de científico que ambos buscan personificar a partir de un doble proceso de identificación:

En determinado momento, el estudiante ve en el tutor el modelo científico, sin embargo también el tutor que tiene su propio modelo ideal se relaciona con el estudiante en términos de formación porque ve en él la posibilidad de encarnar su ideal científico. (González, 140)

A partir de este planteamiento, la autora nos muestra a través de cuatro capítulos la manera como el propio proceso formativo de quienes son investigadores consolidados les habilita para ser herederos de una tradición y poder trasmitirla cuando les llega el tiempo de formar a nuevas generaciones de investigadores.

La segunda parte del título del libro da cuenta del escenario elegido por la autora para desarrollar su trabajo. El Departamento de Biología Celular del Cinvestav constituyó como su unidad de análisis, por múltiples razones, un 
espacio de significativa importancia para ser estudiado, con los rasgos de su institución de origen. El Cinvestav es considerado uno de los centros de investigación que ha contribuido a la institucionalización de la ciencia en México; desde su fundación, a principios de la década de los sesenta, irrumpió como un proyecto innovador, marcando pautas para la profesionalización de la actividad científica en el país, en sus modos particulares de entrenamiento, en la conformación de grupos de investigación y en el tipo de líneas de investigación y de desarrollos tecnológicos que ahí se cultivan.

De este modo, el Departamento de Biología Celular, como señala la autora, representó un microcosmos del Cinvestav que le permitió poner de manifiesto algunas prácticas institucionales y disciplinares que han dejado huella en la ciencia mexicana. A partir del recorrido que la autora realiza sobre la historia institucional de este Departamento - que abarca poco más de medio siglo - se reconoce que este establecimiento destaca por ser un semillero de investigadores y grupos de investigación que han impulsado la emergencia de novedosos campos disciplinarios en el área de la biología en México y América Latina, empezando por el campo disciplinar que le da su nombre, pero también otros como la Patología Experimental y la Biomedicina Molecular.

El Departamento también es reconocido por instaurar rigurosos procesos de selección y formación de estudiantes que redundan y garantizan una formación de nuevas generaciones de jóvenes investigadores de competencia internacional, de los cuales el país se ve favorecido cuando éstos contribuyen con su labor en sus nuevos espacios laborales, más cuando logran colocarse fuera del centro neurálgico de la actividad científica que aún representa la zona metropolitana del país.

Los hallazgos de este trabajo descansan en un cuidadoso proceso de construcción de un objeto de estudio, donde la autora logra armar una consistente trama argumentativa sobre la formación de investigadores del área biológica. Teje finamente múltiples referentes teóricos que abrevan de los estudios sobre el análisis institucional, grupos científicos, procesos de formación y los estudios sociales de la ciencia. Estos elementos son adecuadamente articulados con múltiples fuentes primarias, del orden del análisis de documentos institucionales y de curriculum vitae de investigadores, la construcción y la interpretación de bases de datos sobre su producción científica y el análisis de entrevistas realizadas a destacados investigadores del Departamento de Biología Celular, entre líderes fundadores, primeras y segundas generaciones de investigadores formados en este espacio, así como investigadores procedentes de otros departamentos del Cinvestav. 
Aquí hago un paréntesis para adelantarme en señalar una de las aportaciones que da cuenta de la valía de este trabajo: refiere la propuesta metodológica de reconstrucción y análisis de trayectorias para trabajar el tema de la formación de científicos. Acercarse a las prácticas de los investigadores y los significados que éstas encierran, implicó para la autora la realización de un análisis exhaustivo de los curriculum vite de los investigadores previo a los encuentros que entabló con ellos. El ejercicio interpretativo que ella desarrolló, apoyada en esta herramienta, da cuenta de un fino entramado de elementos de carácter contextual, disciplinar, institucional, grupal y personal que logra articular atinadamente para mostrarnos los procesos de transmisión del oficio científico. Es una propuesta que muestra un gran potencial para aproximarse no sólo al tema de la formación, sino también al estudio de otros fenómenos sociales y educativos que tengan por interés centrarse en los sujetos y sus prácticas.

Lo que se nos enseña en este libro con el análisis del Departamento de Biología Celular del Cinvestav, es que no existen fórmulas predefinidas ni propuestas fijas de formación que configuren carreras científicas exitosas. Sin embargo, la autora plantea la existencia de un ciclo permanente - y yo agregaría, virtuoso - de formación-consolidación entre aprendices y maestros, que busca apoyar, en el caso de los primeros, la gestación de nuevas carreras científicas; y en los segundos, su consolidación como investigadores. Ella advierte que son ciclos con diversas formas de despliegue, en tanto están vinculados con la filosofía de formación que cada maestro investigador se ha forjado a lo largo de su propia experiencia formativa.

Además, la autora logra identificar las funciones y significados que representan determinados periodos y espacios de formación para los investigadores consolidados y sus aprendices. Así, en la tradición disciplinar del Departamento de Biología Celular se reconoce que el doctorado representa para los iniciados un periodo de "infancia científica", de resocialización, donde el tutor funge como el principal vehículo para internalizar el código de valores, normas, modos de comportamiento de una comunidad científica de la que se desea formar parte.

En el texto se observa que el laboratorio de posgrado constituye, por excelencia, el escenario para la socialización de nuevos investigadores. Es un espacio que, en su acepción física y simbólica, configura el lugar de encuentro entre maestros y aprendices. El laboratorio de posgrado es analizado por la autora como campo de entrenamiento y, a la vez, como campo de resistencia; campo de entrenamiento en la medida que, como ella afirma, al ser el investigador el representante de una cultura impuesta en el laboratorio, tiene la tarea de mantener un escenario de que simule las responsabilidades 
que sus aprendices adquirirán al ingresar a la comunidad científica, y campo de resistencia, porque los jóvenes deben demostrar y hacer reconocer sus capacidades y habilidades para avanzar en las diferentes posiciones que se juegan en un laboratorio que opera como seleccionador de los "más aptos y resueltos".

Si el doctorado y el laboratorio doctoral constituyen el inicio de la internalización de un ethos científico, el posdoctorado y la vida en el laboratorio correspondiente lo es de un periodo clave en el inicio hacia la consolidación de la carrera de los jóvenes investigadores. La autora reconoce en el posdoctorado un momento transicional, conforme representa el tiempo y el lugar donde el novel doctor deja de ser un aprendiz de científico para constituirse en un investigador independiente. Es aquí donde "se aprende el oficio", bajo el acompañamiento de un nuevo agente significativo: el supervisor posdoctoral, con quien también se establecerán fuertes lazos de formación.

En el posdoctorado se juega la capacidad del joven investigador para adquirir autonomía. En un contexto en el que importan las condiciones institucionales, las relaciones con actores clave y el capital científico acumulado, esta autonomía tiene como puntos de anclaje el lugar que ocupa el investigador en el laboratorio posdoctoral, sus experiencias en las primeras instituciones donde es contratado, su capacidad para conformar y equipar un laboratorio propio que le permita atraer a sus primeros estudiantes y, con ello, reiniciar el ciclo de formación-consolidación del que alguna vez formó parte al lado de sus maestros.

La autora encuentra en su caso de estudio que el periodo posdoctoral presenta rasgos particulares asociados a la tradición disciplinar y la cultura Cinvestav. Uno importante es, por ejemplo, el principio por buscar colocarse en un posdoctorado en el extranjero, en los laboratorios de punta de sus respectivos campos de especialización. Generalmente, la salida al extranjero va acompañada de un fuerte deseo de retorno al país con el fin de contribuir a la ciencia mexicana. Es un rasgo que, desde mi interpretación por la lectura de los testimonios presentes en la obra, se puede describir como de responsabilidad social, que tiene una alta carga de generosidad y de reconocimiento por la formación recibida en México, que genera el anhelo de aportar a la consolidación de la investigación y la formación de científicos en el país.

Para concluir con el primer propósito de este texto, quiero señalar otro importante núcleo analítico que desarrolla la autora: el papel de la producción científica en el ciclo de formación-consolidación. La publicación de artículos científicos, como medio de comunicación privilegiado para la comunidad científica en este campo disciplinar, es analizado a partir de los rasgos que representa para los estudiantes en su proceso de formación y para los 
mentores investigadores en su camino a la consolidación. De nuevo, la autora recurre al análisis de las trayectorias científicas como herramienta para develar los mecanismos, las cuotas y las estrategias de producción científica empleados en los diferentes periodos formativos, así como las funciones que espacios formativos adicionales al laboratorio, como los seminarios o los denominados días de journals, representan para el aprendizaje de la lectura y la escritura de artículos científicos.

El libro de Julia González representa una valiosa propuesta para pensar los procesos de formación de investigadores en el país. Cuando se acerquen a su lectura reconocerán una apuesta por analizar la formación de jóvenes investigadores que implica mirar procesos cuya concreción, no exenta de contratiempos, de decisiones difíciles, de "virajes de embarcación", está signada por las múltiples vinculaciones que unen a maestros y estudiantes en largas líneas de filiación generacional que buscan heredar una tradición sobre modos de hacer y vivir la actividad científica. Al respecto de los vínculos, comparto una frase de la autora que ilustra mejor la idea antes señalada:

La carrera de un líder investigador en muchos sentidos es indisoluble de la carrera de un nuevo investigador. Finalmente se trata de carreras que se entrecruzan en el camino de la ciencia y dejan entre ambos una marca indeleble de formación y consolidación como científicos. (González: 149)

He mencionado previamente el análisis y la reconstrucción de trayectorias científicas como aportaciones que observo en la obra. Y tengo en la mente un sinnúmero más, pero por razones de espacio añado sólo dos:

La primera, es que este libro abona al conocimiento sobre los procesos de formación y reproducción de la comunidad de investigadores del área biológica en el país; provee de acuciosos análisis para comprender su configuración y el contexto que ha hecho posible la emergencia y el sostenimiento de grupos científicos que han logrado destacar en sus comunidades internacionales y nacionales de referencia. También brinda elementos para pensar los desafíos que actualmente enfrentan las instituciones, sus investigadores y estudiantes para sostener los ciclos virtuosos de formación-consolidación analizados en el libro. Como bien señala la autora, son ciclos de formación a los que no todos los estudiantes acceden, y esto abre nuevas vetas para analizar las razones de esta situación: la constricción de la apertura de nuevos espacios laborales para las nuevas generaciones de investigadores, los esquemas actuales de financiamiento para la ciencia y tecnología, y los nuevos significados que empiezan a surgir en torno al papel de los periodos formativos doctorales y posdoctorales para las actuales generaciones. 
La segunda aportación está pensada para quienes nos dedicamos a la investigación en el campo de las ciencias sociales y de la educación. Con esta obra, la autora brinda una valiosa propuesta de construcción de un objeto de estudio. Nos enseña una manera inteligente de relacionar los niveles micro, meso y macro de aquellos elementos que explican los fenómenos de interés en el estudio y considerar su articulación permanente con las preguntas de investigación y los diversos referentes teóricos que apoyan nuestras interpretaciones. Asimismo, su claro e interesante estilo narrativo es un valioso referente para aprender sobre una escritura académica que atrapa al lector desde sus primeras líneas. 